\title{
Comprehension of degree modifiers by pre-school children: What does it mean to be 'a bit cold'?'
}

\author{
Elena Tribushinina \\ Utrecht Institute of Linguistics, Utrecht University
}

\begin{abstract}
Although even young infants were shown to have some understanding of (adjectival) scalarity, studies of children's spontaneous speech suggest that the acquisition of scalar semantics may not yet be completed by the time children enter primary school. In the present study, this hypothesis is tested by investigating the comprehension of diminishers ('a bit') and consequential degree modifiers ('too') modifying relative adjectives (long, warm) in a group of 5-year-old Dutch-speaking children. Based on earlier production studies, it is hypothesized that by age 6 children are adult-like in their comprehension of 'too' and not yet target-like in the comprehension of 'a bit' modifying relative adjectives. The results of the comprehension experiment demonstrate that some children have already acquired the semantics of both 'too' and 'a bit', whereas others still have trouble understanding combinations of relative adjectives with each of these degree adverbs. Furthermore, poor comprehenders need more time to process sentences with 'a bit' compared to the same sentences with 'too', presumably revealing a greater conceptual complexity of diminishers. These findings are consistent with the idea that the acquisition of scalarity has a protracted time course.
\end{abstract}

Keywords: degree adverbs, adjectives, comprehension, relevance implicatures, child language

\footnotetext{
${ }^{1}$ I am grateful to the two anonymous reviewers for their valuable comments. Many thanks to Jelle Mol, Sophie van der Zee and Viktorija Golovkina for assistance with the experiment and the coding. This research was supported by the Netherlands Organization for Scientific Research (NWO) grant number 275-70-029.
}

Folia Linguistica 48/1 (2014), 255-276. DOI 10.1515/FLIN.2014.008 ISSN 0165-4004, E-ISSN 1614-7308 @ C Mouton de Gruyter - Societas Linguistica Europaea 


\section{Introduction}

Gradability and scalarity are central to human cognition and language. People rarely think in binary terms (e.g. someone is either a good or a bad surgeon); rather we commonly conceptualize objects, properties, quantities and actions in terms of degree. Prototypical markers of scalarity are degree modifiers of adjectives. For example, a surgeon can be said to be sort of good, rather good, pretty good or extremely good. The system of degree modification in the adjectival domain is intriguingly complex due to numerous combinatorial constraints (Stoffel 1901, Klein 1997, Paradis 1997, 2001, Kennedy \& McNally 2005, Tribushinina \& Janssen 2011). For example, so-called maximum-standard absolute adjectives (e.g. clean, correct, perfect) are perfectly acceptable with maximizers (e.g. completely, absolutely) and approximators (e.g. almost, nearly), whereas relative adjectives (e.g. big, cheap, cold) are commonly unacceptable with totality modifiers (e.g. completely, absolutely). Furthermore, there is quite a lot of cross-linguistic variability in this domain. For example, in Germanic languages things cannot be 'completely high' or 'completely low', whereas in Slavic languages negative-pole relative adjectives such as 'low' and 'poor' are perfectly acceptable with maximizing adverbs (Tribushinina 2008, 2009, 2011a).

Despite the pervasiveness of degree modification in language use, fairly little is known about the acquisition of degree modifiers by children, and the scarce evidence available in the literature is rather controversial. On the one hand, experimental results reported in Syrett \& Lidz (2010) seem to suggest that already by age 3 , children are sensitive to the relevant combinatorial restrictions in the domain of degree. In their word-learning experiment, 30-month-olds were presented with novel adjectives that were either unmodified (e.g. wuggin) or modified by completely or very (completely wuggin vs. very wuggin). In the completely-condition, the infants were more likely to attend to properties associated with maximum-standard adjectives (e.g. transparent, straight), whereas in the very-condition they attended more to relative properties (e.g. tall, long). Syrett \& Lidz (2010) conclude that by age 3 , children are able to use the semantic information in the degree adverb to assign an interpretation to a novel adjective.

On the other hand, corpus studies of spontaneous use of degree adverbs in child speech indicate that children have not fully acquired the semantics and syntax of degree adverbs by age 6 (Gathercole 2009, Tribushinina 
2011b, Tribushinina \& Gillis 2012). These studies show that the first combinations of adjectives and degree adverbs are primarily used as rote-learnt units; therefore, the error rate before age 3 is very low. However, once children start using such combinations productively, they also start making overgeneralization errors such as a bit enough and heel beter 'very better'. Furthermore, there is some indication that even adverb-adjective combinations that do appear adult-like on the surface are not interpreted in an adult-like way. Notice, however, that from (spontaneous) production data alone we cannot be absolutely sure what kind of interpretation children attach to linguistic items. In order to establish whether children's understanding of relative adjectives modified by degree adverbs is really not adult-like by age 6 , we need comprehension experiments.

A case in point is the comprehension of diminishers, i.e. degree adverbs denoting a small degree of a property such as a bit and slightly, used in combination with relative adjectives. In languages such as English and Dutch adults commonly use combinations such as a bit cheap/een beetje goedkoop and a little big/een beetje groot to denote an undesirable excess of a property. Put differently, these combinations function as polite counterparts of consequential degree constructions with too (too cheap, too big) (Paradis 1997, 2001, Tribushinina 2008, 2009). By way of illustration consider examples (1)-(4) from the Corpus of Spoken Dutch:

(1) Ik vind het altijd wel lekker als 't een beetje koud is.

'I like it when it is a bit cold.'

(2) A: Vind't wel een beetje koud hier hè?

'I think it's a bit cold here, don't you?'

B: De verwarming staat aan hoor.

'But the heating is on you know.'

(3) Als ze achttien zijn, zijn ze al een beetje groot en hopelijk dan wijs ook natuurlijk hè.

'When they are eighteen, they are already a bit big and hopefully also wise of course.'

(4) Maar ja 'k peis dat dat een beetje groot is want da's maar uh ja een kleine twintig mensen die daar zitten of zo zuh.

'But yeah I think that that one is a bit big because there are less than twenty people or so working there.'

In sentences (1) and (3), the adjectives koud 'cold' and groot 'big', respectively, are used primarily as descriptors. In these cases, the diminisher een 
beetje 'a bit' mitigates their meaning and suggests that the designated property (coldness and bigness/adulthood) was present to a certain small extent. By contrast, the same modifier-adjective combinations in (2) and (4) are used as understatements to imply that there was too much of the property in a specific situation. So A's utterance in (2) is interpreted by the hearer (B) as an indirect request to turn on the heating or as an indirect reproach that the room is too cold. Likewise, the office in (4) is deemed too big for a small firm of less than twenty people. In fact, purely descriptive uses of relative adjectives taking diminishers are extremely rare; such combinations are more often used to denote an undesirable excess of a property (Tribushinina 2008, 2009, cf. Pander Maat 2006, Holleman \& Pander Maat 2009). Argumentative uses of relative adjectives with diminishers are also common in child-directed speech. Consider the following examples from the Groningen corpus (Bol 1995) in the CHILDES database (MacWhinney 2000):

(5) (from input to Abel, age 2;5)

Nou, ga daar maar niet mee gooien. Want die zijn een beetje groot.

'Well don't throw with those. Because they are a bit big.'

(6) (from input to Matthijs, age 3;1)

Eveline: Kan Frederike ook een staartje?

'Can Frederike also get a ponytail?'

Child: Ja.

'Yes'.

Eveline: Nou, die heeft wel een beetje kort haar denk $i k$.

'Well her hair is a bit short, I think.'

In (5), Abel is advised not to throw with blocks because they are too big for that. Similarly, Eveline in (6) suggests that Frederike cannot have a ponytail because her hair is too short for that.

Corpus studies of spontaneous child speech seem to suggest that children, unlike adults, tend to use combinations of relative adjectives with diminishers compositionally (i.e. to express a small degree of the designated property) rather than argumentatively (i.e. to express an undesirable excess) (Tribushinina 2011a, Tribushinina \& Gillis 2012). See, for instance, the following two fragments of mother-child interactions from the Groningen corpus: 
(7) (Abel, age 2;2)

Mother: Misschien als je de rails hier onderdoor doet.

'Perhaps if you put the rails underneath.'

Mother: Die is hoger.

'That one is higher.'

Mother: Misschien dat (he)t dan wel lukt.

'Perhaps it will work out then.'

Mother: Ik kan het slecht aanzien.

'I can't see that'.

Child: Kan niet.

'It can't.'

Mother: Nee, kijk.

'No, look.'

Child: Kan niet.

'It can't.'

Mother: Kan niet.

'It can't.'

Mother: Kijk, volgens mij, als je zo doet zo dan kan ie wel.

'Look, I think if you do it like this, it will work.'

Mother: Ja.

'Yes'

Child: Kan niet.

'It can't.'

Child: Beetje groot moet a zo.

'It must (become) (a) bit big like that.'

Mother: Een beetje groot?

'A bit big?'

Mother: Wat is een beetje groot?

'What is a bit big?'

(8) (Abel, 2;3)

Child: Ik wil ook honing.

'I also want honey.'

Child: Beetje $x x$.

'(A) bit xxx.'

Mother: Beetje wat?

(A) bit what?

Child: $\quad x x$ koppie thee pakken.

'xx take cup of tea.' 
Gerard: Hm, lekker.

'Hm, great.'

Gerard: Nou.

'Well.'

Mother: Warme thee, hoor.

'Hot tea, you know.'

Gerard: Daar valt de boer.

'The farmer is falling down.'

Child: Deze beetje warm.

'This (a) bit hot.'

Mother: Was die nog een beetje warm?

'Was it still a bit hot?'

Mother: Te warm?

'Too hot?'

Child: Deze xx beetje koud.

'This xx (a) bit cold.'

Mother: Oh, koud.

'Oh, cold.'

(a few minutes later)

Gerard: Ja, ga maar eerst even wat drinken.

'Yes, but go have something to drink first.'

Mother: Wat zei je?

'What did you say?'

Child: Beetje warm.

'(A) bit hot.'

Child: Koud, beetje koud.

'Cold, (a) bit cold.

Mother: Beetje koud.

'(A) bit cold.'

Mother: Nou, precies goed.

'Well, just right then.'

Child: Beetje koud.

'(A) bit cold.'

Mother: Lekker is het.

'It is tasty'.

Child: $A h$.

'Ah.'

Mother: Was het koud?

'Was it cold?' 


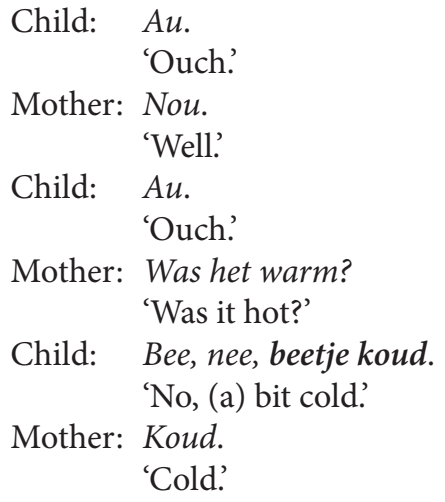

In the situation discussed in (7), Abel wants to make a bridge higher so that the toy train can ride under it. The child phrases this wish as beetje groot moet '(a) bit big must'. This use is incompatible with a 'too'-interpretation and sounds more like a comparative marker (the bridge must be made a bit bigger/higher). Similarly, in (8) the child describes the temperature of the tea as beetje warm '(a) bit hot', which the mother immediately interprets as 'too hot'. From the rest of the interaction, it becomes clear that this is not really what the child meant with beetje warm. Abel dubs the tea 'a bit hot' and 'a bit cold' at the same time probably trying to refer to the middle part of the scale, i.e. a temperature between hot and cold. This is, at least, how the mother re-interprets Abel's utterances, as is evident from her response nou precies goed 'just right then'.

Tribushinina (2011b) analyzed a number of fragments such as (7) and (8) in longitudinal corpora of nine children acquiring Netherlandic Dutch (Tribushinina 2011b) and suggests that children commonly use combinations of diminishers and relative adjectives in contexts where a 'too'-interpretation is unlikely. The results of a cross-sectional study of spontaneous child speech in Belgian Dutch (Tribushinina \& Gillis 2012) confirm these observations and demonstrate that even 6-year-olds seem to use such combinations in a non-adult-like way. Notice, however, that from production data, such as interactions in (7) and (8), we cannot be confident that children indeed fail to interpret phrases such as a bit cold in an argumentative way (i.e. meaning 'too cold'), and only treat such combinations compositionally (i.e. meaning 'cold to a small degree'), since we do not know what kind of interpretations they attached to the linguistic items in their speech. 
Another problem with corpus studies of degree modification is that adjectives in general and degree-modified adjectives in particular are quite infrequent in spontaneous speech (Tribushinina \& Gillis 2012); hence generalizations from these data are unwarranted.

There has hardly been any research targeting comprehension of degree modifiers by children. In one such study, Berndt \& Caramazza (1978) found that pre-schoolers have more trouble understanding diminishers than intensifiers. This pattern is, in their view, related to a greater conceptual complexity of negative-pole terms, as well as to their lower frequencies in the input language.

\section{This study}

On the basis of the prior research discussed above, I hypothesize that preschool children do not understand the semantics of diminishers used argumentatively in combination with relative adjectives. At the same time, children are expected to understand the semantics of the counterpart construction with 'too' (Tribushinina \& Gillis 2012). These predictions will be tested in a comprehension experiment with 5-year-old Dutch-speaking children in Experiment 2.

Before testing children's comprehension of degree-modified relative adjectives, it was necessary to make sure that adults indeed interpret combinations such as a bit warm in terms of an undesirable excess of a property. This step was needed because semantic research making these claims drew on production data and introspection rather than on comprehension measures in adults (Paradis 1997, 2001, Tribushinina 2008, 2009). Therefore, in Experiment 1 Dutch-speaking adults were asked to judge whether, in their view, a person pronouncing a specific utterance about a product (e.g. Die vind ik een beetje lang 'That one I find a bit long') would like to buy that product or not.

The children were tested in Experiment 2 using a procedure developed by Schulze, Grassmann \& Tomasello (2013) and Tribushinina (2012). Schulze, Grassmann \& Tomasello (2013) demonstrated that pre-schoolers are able to make relevance inferences when inference-drawing is naturally embedded in an ongoing interaction (e.g. a game), is supported by joint attention and is goal-oriented. For example, children as young as 3 years of age understand that the sentence I find elephants good may function as 
an indirect request to give an elephant to a person or as an indirect rejection of another toy animal, rather than a mere description of a situation/ referent.

In a similar vein, Tribushinina (2012) used a scenario of a shopping game to investigate children's developing ability to draw relevance inferences from sentences where an indirect acceptance or refusal had to be inferred from an evaluative adjective describing the person's attitude towards an object. Dutch-speaking children aged 2, 3 and 5 were asked to decide whether a customer wanted to buy a product based on a description, such as Die vind ik (niet) interessant 'That one I find (not) interesting' or Die vind ik (niet) lelijk 'That one I find (not) ugly'. If they thought the customer wanted the product, they were asked to put it into a shopping basket; or otherwise, put it back on the table. Comprehension of indirect utterances was compared to the comprehension of direct requests (e.g. Yes, thank you) or refusals (No, I don't want it). Even the youngest children in this study performed above chance. However, 2- and 3-year-olds made more errors with the most complex, indirect negative items (e.g. Die vind $i k$ saai 'That one I find boring') than 5-year-olds and adults. These results show, in line with Schulze, Grassmann \& Tomasello (2013), that even very young children are able to grasp the argumentative orientation of evaluative adjectives. In the present study, this paradigm will be employed for studying the comprehension of degree-modified relative adjectives. Relative adjectives, like evaluative ones, denote a context-dependent property. However, relative adjectives such as tall are different from evaluative ones such as clever in that they denote measurable properties and can refer to the whole scale (cf. Tom is taller than Bill, but they are both short vs. ?Tom is cleverer than Bill, but they are both stupid) (Bierwisch 1989, Tribushinina \& Gillis 2012).

Experiment 2 tests the ability of 5-year-old Dutch-speaking children to interpret combinations of the diminisher een beetje 'a bit' with relative adjectives in an argumentative way (see Pander Maat 2006, Holleman \& Pander Maat 2009), i.e. as denoting an undesirable excess of a property. Since een beetje 'a bit' in such contexts is used as an indirect counterpart of the consequential degree modifier te 'too', I will compare children's performance with the same relative adjectives in both types of frames - in combination with een beetje 'a bit' and in combination with te 'too'. Combinations of evaluative adjectives with the intensifier heel 'very' will be used as fillers. Since even 2-year-olds were shown to be able to grasp the 
argumentative orientation of evaluative adjectives (Tribushinina 2012), the addition of the intensifier heel 'very' is not likely to make the task more difficult for 5-year-olds.

Based on the observations from spontaneous child speech reported in prior research (Tribushinina 2011b, Tribushinina \& Gillis 2012), it might be hypothesized that children's comprehension of relative adjectives taking diminishers will not be adult-like at age 5. More specifically, 5-yearolds may fail to understand that these combinations are usually used as polite rejections rather than mere descriptions of a property (and a small degree thereof). Combinations of relative adjectives with 'too' should be less difficult to interpret. Firstly, intensfiers are known to be less problematic for children than diminishers (Berndt \& Caramazza 1978). Secondly, the meaning of an undesirable excess that is only implied in the case of 'a bit' is explicitly expressed by 'too'. Hence, it can also be hypothesized that sentences with 'a bit' will take more processing time compared to the same sentences with 'too', since interpretation of non-literal utterances incurs an additional processing cost (Bott \& Noveck 2004). From the point of view of conceptual complexity as well, diminishers (being negative-pole items) may cost more processing time than positive-pole intensifiers such as too (Berndt \& Caramazza 1978).

\section{Experiment 1}

\subsection{Participants}

Forty undergraduates of Utrecht University, twenty-seven females and thirteen males, took part in the experiment in return for course credit. All participants were monolinguals speakers of Netherlandic Dutch.

\subsection{Materials and procedure}

This was a paper-and-pencil experiment. The participants were given a response sheet containing a list of forty utterances, each describing a specific product (e.g. bike, umbrella). They were asked to indicate whether a person reacting to the product in that particular way was likely (to be willing) to buy it $(+)$ or not $(-)$.

The list contained twenty test items with relative adjectives modified by either een beetje 'a bit' $(\mathrm{N}=10)$ or te 'too' $(\mathrm{N}=10)$, and twenty filler items 
containing an evaluative adjective modified by heel 'very'. All sentences started with Die vind ik . . . ('That one I find ...'), followed by a degree adverb modifying an adjective, as in Die vind ik een beetje kort'That one I find a bit short'. The same relative adjectives were used with een beetje and te; half of them were positive (e.g. groot 'big', duur 'expensive', warm 'warm') and half negative (e.g. klein 'small', goedkoop 'cheap', koud 'cold'). It was important to use the same adjectives across both conditions. If each of the degree adverbs modified a different set of adjectives, we would not be able to decide whether possible differences in outcome were due to varying complexity of degree adverbs or due to differences in adjective processing.

The fillers were used to counterbalance the negative responses associated with the target trials, thus avoiding a refusal bias, since all 'a bit' and 'too' utterances suggested a refusal interpretation. As such, there were more positive evaluative adjectives $(\mathrm{N}=15)$ than negative ones $(\mathrm{N}=5)$. Further, although an evaluative adjective as such would be sufficient to suggest rejection or acceptance of a product, the intensifier 'very' was added in order to make the evaluative sentences structurally similar to the target items.

The adjective-object pairings were carefully selected by three adult speakers of Netherlandic Dutch on the basis of two criteria: (i) word complexity suitable for 5-year-old children; (ii) naturalness of adjective use in each specific combination (some of the literal translations into English may sound less natural).

The sentences were presented to all subjects in the same order, pseudorandomized with respect to two factors: polarity of the target response (product acceptance or rejection) and degree modifier. The same adverb and target response did not occur in more than two subsequent sentences. The full list of the stimuli used in the experiment is presented in Table 1.

Table 1. Stimuli (Experiment 1)

\begin{tabular}{|c|c|c|c|}
\hline No & Degree modifier & Adjective & Picture \\
\hline 1 & heel & raar 'strange' & hat \\
\hline 2 & een beetje & warm 'warm' & pullover \\
\hline 3 & heel & mooi 'pretty' & bow \\
\hline 4 & heel & stom 'stupid' & toy monster \\
\hline 5 & te & goedkoop 'cheap' & clock \\
\hline 6 & heel & lekker 'delicious' & strawberry \\
\hline 7 & een beetje & makkelijk 'easy' & puzzle \\
\hline
\end{tabular}


Table 1. (cont.)

\begin{tabular}{rlll}
\hline No & Degree modifier & Adjective & Picture \\
\hline 8 & heel & finn 'fine' & umbrella \\
9 & te & lang 'long' & pencil \\
10 & heel & plezierig 'pleasant' & swing \\
11 & een beetje & koud 'cold' & snowman \\
12 & heel & grappig 'funny' & elephant \\
13 & heel & lelijk 'ugly' & socks \\
14 & te & groot 'big' & table \\
15 & heel & leuk 'nice' & bear \\
16 & te & makkelijk 'easy' & balance bike \\
17 & een beetje & goedkoop 'cheap' & sunglasses \\
18 & heel & cool 'cool' & guitar \\
19 & een beetje & klein 'small' & shoes \\
20 & te & duur 'expensive' & cap \\
21 & heel & goed 'good' & tennis racket \\
22 & te & koud 'cold' & ice-cream \\
23 & een beetje & groot 'big' & bicycle \\
24 & heel & slim 'clever' & pocketknife \\
25 & heel & gek 'crazy' & alien \\
26 een beetje & moeilijk 'difficult' & calculator \\
27 & heel & smakelijk 'tasty' & sandwich \\
28 & heel & interessant 'interesting' & mushroom \\
29 & te & warm 'warm' & gloves \\
30 & een beetje & kort 'short' & rope \\
31 & heel & gezond 'healthy' & apple \\
32 & te & klein 'small' & dice \\
33 & te & moeilijk 'difficult' & book \\
34 & heel & schattig 'cute' & duck \\
35 & een beetje & duur 'expensive' & ball \\
36 & heel & lief 'sweet' & dog \\
37 & te & kort 'short' & skirt \\
38 heel & vies 'foul' & carrot \\
39 & heel & prettig 'pleasant' & pillow \\
40 een beetje & lang 'long' & scarf \\
\hline & &
\end{tabular}




\subsection{Scoring}

Responses were scored as target-like if the participant put a minus (-) in the boxes containing relative adjectives and negative evaluative adjectives, and a plus (+) in the boxes containing positive evaluative adjectives.

\subsection{Results}

Table 2 summarizes the median proportions of target responses by condition.

Table 2. Proportion of target responses in the adult group (Experiment 1)

\begin{tabular}{llll}
\hline & Een beetje 'a bit & Te 'too' & Fillers \\
\hline Median & 1.00 & 1.00 & 1.00 \\
Range & 0.20 & 0.20 & 0.05 \\
\hline
\end{tabular}

As is evident from Table 2, adult performance was consistent with the predictions made on the basis of prior semantic research. The subjects rejected the product when its description contained a relative adjective modified by either te or een beetje. For the filler items, the choice depended on the polarity of the evaluative adjective. A Friedman test revealed no differences between the three conditions $(p=1.0)$. It can be concluded that the stimuli are suitable for testing children's comprehension of relative adjectives in consequential degree constructions. This will be done in Experiment 2.

\section{Experiment 2}

\subsection{Participants}

Thirty-three 5-year-olds, eighteen girls and fifteen boys, participated in the experiment (mean age: 5;5, age range: 5;0-6;0). The subjects were recruited through two primary schools in the Utrecht area and one in the Rotterdam area. The children were monolingual speakers of Netherlandic Dutch and came primarily from middle-class families. 


\subsection{Materials and procedure}

The procedure developed by Tribushinina (2012) for testing the comprehension of evaluative adjectives used for indirect requests/refusals was taken as a basis and adjusted for the purposes of this study. The children were playing a shopping game in which they had to decide whether a customer wanted to buy a product, based on a description by that customer indirectly conveying his/her argument to buy it or not (e.g. That one I find too big).

The test materials were a hand puppet (Jan Klaassen, a traditional puppet similar to Kasperle), a small shopping basket, a small garbage can and forty black-and-white computer-generated images, presented on $7 \times 7 \mathrm{~cm}$ cards. The pictures depicted products that the puppet was offered to buy.

The children were tested individually in a quiet room at their school. The child was sitting at a table and the investigator with a hand puppet was sitting in front of the child. The participants were invited to play a shopping game with the puppet. In the game, the child was a seller and the puppet was a customer. The subject was given a pile of forty pictures depicting the products and was asked to offer the products to the puppet one by one. The puppet then commented on the product according to the scheme listed in Table 1. For instance, when presented with a picture of a pullover, the puppet said Die vind ik een beetje warm 'That one I find a bit warm'. The intonation was kept as neutral as possible. The child was then to decide whether the customer wanted to buy the product or not. If s/he thought the puppet wanted the product, the child was to put the picture into the toy shopping basket. If the child thought the customer did not want the product, s/he was asked to put the picture into the garbage can. The position of the shopping basket and the garbage can (left or right) with respect to the child was randomized among the participants. Both the shopping basket and the garbage can were located at a 50-centimetre distance from the child. If the child got distracted, the target sentence was repeated once. It took the children five to ten minutes to complete the task. The experimental sessions were videotaped by a second investigator.

\subsection{Coding and scoring}

Both off-line and on-line measures were assessed. The off-line measure used in this study is the proportion of target responses to a test item. In the context of indirect requests, relative adjectives modified by te 'too') and 
een beetje 'a bit' should evoke a negative interpretation (refusal to buy a product). The target response for evaluatives depends on the polarity of the adjective. For example, That one I find very delicious should be understood as an indirect acceptance of the product, whereas That one I find very stupid should be taken as a refusal. The responses to relative adjectives and negative evaluatives were scored as correct if the participant put the card into the garbage can. The responses to positive evaluatives were scored as correct if the participant put the card into the shopping basket.

The on-line measure used in this study was reaction times (RTs). The RTs were coded by means of the ELAN 3.8.1 software. The starting point was defined as the moment at which the last word of a sentence (adjective) had been uttered completely, and the endpoint was the moment at which the child released the card into either the shopping basket or the garbage can. Coding was performed by two research assistants. Inter-coder agreement was 93 per cent.

\subsection{Results}

As expected, the children had little difficulty interpreting the filler utterances with evaluative adjectives, which is confirmed by the median proportion of target responses $(M d n=0.95)$. Table 3 summarizes the results for the target items by condition ('too' vs. 'a bit').

A Wilcoxon Signed-ranks test indicated that there was no significant difference between the two conditions $(p=0.60)$. Notice, however, that the variance was very large in both conditions. In other words, there were children who performed very well and children who performed very poorly. For both conditions, there was a spreading of the proportion of target responses from o to 1.o. A Spearman's Rank Order correlation was run to determine the relationship between the children's performance on 'too' and 'a bit' trials. There was a strong, positive correlation between the subjects' performance in the two conditions, which was statistically significant, $r_{s}(31)=0.89, p<$ 0.001 . This means that the children who performed well on the 'too' trials

Table 3. Proportion of target responses in the child group (Experiment 2)

\begin{tabular}{lll}
\hline & Een beetje 'a bit & Te 'too' \\
\hline Median & 0.80 & 0.70 \\
Range & 1.00 & 1.00 \\
\hline
\end{tabular}


also performed well on the 'a bit' trials. Poor performance on the test trials was not due to a failure to understand the task, since the children who performed poorly on the target items performed well in the filler condition. There was a weak non-significant correlation between the children's performance on fillers and on 'a bit' trials, $r_{s}(31)=0.22, p=0.22$. The correlation between the subjects' performance in the filler condition and in the 'too' condition was very low and non-significant, $r_{s}(31)=0.07, p=0.72$.

A closer scrutiny of individual performance revealed that 22 of 33 children $(67 \%)$ were between $60 \%$ and $100 \%$ correct in both conditions; and half of those $(\mathrm{N}=11)$ were between $90 \%$ and $100 \%$ correct on both adverbs. Eleven children (33\%) were below $60 \%$ correct in both conditions; half of those $(\mathrm{N}=6)$ only succeeded in $30 \%$ of the trials or less. The children's age was not significantly correlated with their performance on 'too' $\left(r_{s}(31)=0.05, p=0.77\right)$ and 'a bit' trials $\left(r_{s}(31)=0.01, p=0.95\right)$.

Let us now look at the children's RTs in the two conditions. A Wilcoxon Signed-ranks test showed that the RTs in the 'a bit' condition $(M=1.69$, $S D=0.57)$ were not significantly longer than the RTs in the 'too' condition $(M=1.65, S D=0.68)(p=0.21)$. To exclude possible order effects (due to repeated measures with the same adjectives across the two conditions), I compared RTs for te and een beetje in the first five trials and in the last five trials with each of these adverbs. Wilcoxon Signed-ranks tests showed no significant differences between RTs for te and een beetje in the first half of the experiment $(p=0.46)$, nor in the second half of the experiment $(p=0.08)$.

Since the analysis of individual performance revealed that some children were (almost) target-like in both conditions, whereas other children performed poorly on both 'too' and 'a bit' trials, it seems worthwhile to compare the RTs by group, divided by median split in off-line performance (good comprehenders: $\geq 70 \%$ correct in one or both conditions; poor comprehenders: $<70 \%$ in one or both conditions). For good comprehenders, there was no significant difference between RTs in the two conditions $(p=0.88)$, whereas poor comprehenders spent more time on 'a bit' trials $(M=1.70$, $S D=0.59)$ than on 'too' trials $(M=1.47, S D=0.61), Z=2.06, p=.04$.

\section{Discussion and conclusion}

The research reported in this article is one of the first attempts to assess comprehension of degree modifiers in children. More specifically, this 
study investigated whether 5 -year-olds understand that combinations of relative adjectives with diminishers (e.g. $a$ bit short) often denote an undesirable excess of a property and are close in meaning to combinations with too (Paradis 1997, 2001, Tribushinina 2008, 2009). The paradigm of a shopping game was chosen, since it provides a felicitous argumentative context for interpreting indirect utterances as acceptance or refusal to buy a product. In this context, even 2-year-old toddlers were shown to be able to understand indirect utterances with evaluative adjectives (Tribushinina 2012).

The paper-and-pencil experiment with Dutch-speaking adults (Experiment 1) confirmed that language users indeed interpret relative adjectives modified by te 'too' and een beetje 'a bit' as a negative evaluation of an object leading to its rejection rather than as a mere description. If combinations such as een beetje kort 'a bit short' were taken as pure descriptors, then the adults would probably have chosen the acceptance and the refusal interpretation at about equal rates. However, they overwhelmingly understood sentences with relative adjectives modified by the diminisher een beetje (e.g. een beetje lang 'a bit long') the same way as they understood these adjectives modified by te (e.g. te lang 'too long'), that is, as indirect refusals.

In Experiment 2, the same stimuli were used in a shopping game with 5 -year-olds acquiring Dutch. In this game, the children had to decide whether a puppet wanted to acquire a product based on the puppet's indirect judgements, such as That one I find too long. The children had no trouble interpreting filler sentences with evaluative adjectives (e.g. That one I find very ugly), which is not surprising in view of earlier findings that even 2-year-old toddlers are able to understand sentences with evaluative adjectives as indirect requests (for positive items) or refusals (for negative items) (Tribushinina 2012).

For the experimental conditions ('too' and 'a bit'), the results were mixed. Based on investigations of adjective and adverb use in spontaneous child speech (Tribushinina 2011b, Tribushinina \& Gillis 2012), it was hypothesized that 5-year-olds would be non-adult-like in their interpretation of relative adjectives modified by the diminisher een beetje 'a bit', but would have less trouble interpreting the same adjectives modified by te 'too'. This difference was expected to be visible in both off-line measures (proportion of target responses) and on-line measures (RTs). The results revealed no differences between 'too' and 'a bit' on off-line and on-line measures. 
Importantly, children who performed well with 'too' also performed well with 'a bit'. A closer look at the individual performance revealed that there were two groups of children: good comprehenders (who showed almost adult-like behaviour) and bad comprehenders (who got less than $60 \%$ correct with both adverbs). Good comprehenders did not need more time to process 'a bit' compared to 'too', probably because both types of constructions involved drawing a relevance inference (inferring rejection based on an object description). In contrast, bad comprehenders spent more time in the 'a bit' condition than in the 'too' condition. How can we explain this difference? At the outset of this study, it was hypothesized that the interpretation of een beetje takes more processing time because it involves an additional inferential step (the meaning of excess is literally expressed by te 'too' and only implied by een beetje 'a bit'). Given the pattern of results reported above, this explanation does not seem tenable. An additional inferential step would only be relevant in children who actually did interpret een beetje as a marker of undesirable excess (good comprehenders), but not in children who failed to draw the inference (poor comprehenders). Good comprehenders did draw the inference, but did not need more time for the diminisher trials. Poor comprehenders failed to draw the inference; so longer RTs in this case are more likely to be related to the greater semantic complexity and lower frequencies of diminishers (Berndt \& Caramazza, 1978).

On the basis of these results, we can refute the hypothesis that children up to age 6 do not understand the semantics of relative adjectives taking diminishers. Two-thirds of the children had no difficulty correctly interpreting combinations of relative adjectives with te and een beetje, as evidenced by high rates of correct performance and similar RTs in both conditions. However, one-third of the children did have trouble with both te 'too' and een beetje 'a bit'. Their failure on the target items was not due to misunderstanding the task, since both good and poor comprehenders were overwhelmingly target-like on the filler items. Notice also that even 2-year-olds succeed on this task, if they understand the linguistic material involved (Tribushinina 2012). So it can be concluded that some 5-year-olds have not yet mastered the semantics of the degree modifiers te and een beetje. This result is consistent with the findings from earlier corpus investigations suggesting that children sometimes use diminishers such as een beetje in a non-adult-like way. Poor performance with te has not yet been reported in the literature on Dutch child language; the existing studies 
mention apparently target-like use of te from age 3 onwards (Tribushinina 2011b; Tribushinina \& Gillis 2012). However, research on English child language reported in Gathercole (2009:339) has provided some evidence that consequential degree modifiers such as too and enough are more difficult for language learners than boosters such as very (see also Von Stechow 1984). Boosters only profile a particular extent of a property in an entity, whereas consequential degree modifiers additionally imply a comparison of a degree to some desired range on a scale. Both children in Gathercole's dense database started using too as a mere intensifier, i.e. as a synonym of very. Target-like uses of too as a consequential degree marker emerged after age 3;6, but the development of their use was gradual and slow. Errors in the use of too were attested in the speech of children between 5 and 6 years of age. In view of these results, it is possible that poor comprehenders in the present study interpreted the Dutch te 'too' as a booster rather than as a consequential degree modifier.

To recapitulate, this study has only partly confirmed the hypothesis formulated on the basis of earlier production studies that pre-schoolers are target-like in their comprehension of 'too' and non-adult-like in their comprehension of 'a bit' modifying relative adjectives. Some 5-year-olds children have no trouble understanding these degree constructions, whereas others have not yet mastered the semantics of the two degree modifiers. Furthermore, diminishers appear to be more complex than intensifiers, which was confirmed by longer reaction times in the struggling group. Future research should test to what extent these findings are generalizable to other (types of) degree adverbs.

All in all, the findings suggest that the even though 30-month-old infants have some sensitivity for scalar structures (Syrett \& Lidz 2010, Tribushinina \& Gillis 2012), the acquisition of (adjectival) scalarity is a long process that extends far beyond age 3 (see Gathercole 2009, Verbuk 2009, Tribushinina 2011b). The current results also provide additional insights into the acquisition of relevance implicatures. The results of this study are compatible with earlier research (Tribushinina 2012, Schulze, Grassmann \& Tomasello 2013) claiming that the ability to draw relevance inferences emerges earlier than what has been traditionally assumed in the literature (Elrod 1987, Bernicot, Laval \& Chaminaud 2007, Loukusa, Leinonen \& Ryder 2007, Verbuk \& Schultz 2010). Young children can draw relevance inferences if inference-drawing is a natural part of an on-going interaction supported by joint attention (Tribushinina 2012, Schulze, Grassmann \& 
Tomasello 2013). Notice that Tribushinina (2012) used evaluative adjectives such as 'good' and 'delicious' to test implicature comprehension in young children. An alternative explanation of the results might be that children do not compute an inference, but rather rely on associations being part of their world knowledge (e.g. people usually buy things that are pretty and disprefer things that are ugly). Relative adjectives used in this study provide a more stringent test of children's ability to draw relevance inferences, since these adjectives as such (i.e. outside context and construction) are less straightforwardly associated with particular (positive or negative) judgments. Thus, if children interpret a sentence such as That one I find a bit long as an indirect refusal, they do seem to draw an inference that is not solely based on their world knowledge.

\section{References}

Berndt, Rita Sloan \& Alfonso Caramazza. 1978. The development of vague modifiers in the language of pre-school children. Journal of Child Language 5: 279-294.

Bernicot, Josie, Virginia Laval \& Stephanie Chaminaud. 2007. Nonliteral language forms in children: In what order are they acquired in pragmatics and metapragmatics? Journal of Pragmatics 39: 2115-2132.

Bierwisch, Manfred. 1967. Some semantic universals of German adjectivals. Foundations of Language 3: 1-36.

Bol, Gerard W. 1995. Implicational scaling in child language acquisition: The order of production of Dutch verb constructions. In Maaike Verrips \& Frank Wijnen, eds. Papers from the Dutch-German colloquium on language acquisition. Amsterdam: Institute for General Linguistics, 1-13.

Bott, Lewis \& Ira A. Noveck. 2004. Some utterances are underinformative: The onset and time course of scalar inferences. Journal of Memory and Language 51: 437-457.

Elrod, Mimi Milner. 1987. Children's understanding of indirect requests. Journal of Genetic Psychology 148: 63-70.

Gathercole, Virginia C. Mueller. 2009. "It was so much fun. It was 20 fun!" Cognitive and linguistic invitations to the development of scalar predicates. In Virginina C. Gathercole, ed. Routes to language: Studies in honor of Melissa Bowerman. New York: Pyschology Press, 319-443.

Holleman, Bregje C. \& Henk Pander Maat. 2009. The pragmatics of profiling: Framing effects in text interpretation and text production. Journal of Pragmatics 41: 2204-2221. 
Kennedy, Christopher \& Louise McNally. 2005. Scale structure, degree modification, and the semantics of gradable predicates. Language 81: 345-381.

Klein, Henny. 1997. Adverbs of degree in Dutch (Groningen Disserations in Linguistics 21). Groningen: University of Groningen.

Loukusa, Soile, Eeva Leinonen \& Nuala Ryder. 2007. Development of pragmatic language comprehension in Finnish-speaking children. First Language 27: 279-296.

MacWhinney, Brian. 2000. The CHILDES project: Tools for analyzing talk. Mahwah, NJ: Lawrence Erlbaum Associates.

Pander Maat, Henk. 2006. Subjectification in gradable adjectives. In Angeliki Athanasiadou, Costas Canakis \& Bert Cornillie, eds. Subjectification: Various paths to subjectivity. Berlin: Mouton de Gruyter, 279-322.

Paradis, Carita. 1997. Degree modifiers of adjectives in spoken British English (Lund Studies in English 92). Lund: Lund University Press.

Paradis, Carita. 2001. Adjectives and boundedness. Cognitive Linguistics 12: 47-65.

Schulze, Cornelia, Susanne Grassmann \& Michael Tomasello. 2013. 3-year-old children make relevance inferences in indirect verbal communication. Child Development 84: 2979-2093.

Stoffel, Cornelis. 1901. Intensives and down-toners: A study in English adverbs. Heidelberg: Carl Winter.

Syrett, Kristen \& Jeffrey Lidz. 2010. 30-month-olds use the distribution and meaning of adverbs to interpret novel adjectives. Language Learning and Development 6: 1547-3341.

Tribushinina, Elena. 2008. Cognitive reference points: Semantics beyond the prototypes in adjectives of space and colour (LOT Dissertation Series 192). Utrecht: LOT.

Tribushinina, Elena. 2009. Reference points in linguistic construal: Scalar adjectives revisited. Studia Linguistica 63: 233-260.

Tribushinina, Elena. 2011a. Boundedness and relativity: A contrastive study of English and Russian. Languages in Contrast 11: 106-128.

Tribushinina, Elena. 2011b. Piecemeal acquisition of boundedness: Degree modifiers of adjectives in Dutch child language. In Gregory Bochner, Philippe de Brabanter, Mikhail Kissine \& Daniela Rossi, eds. Cognitive and empirical pragmatics: Issues and perspectives. Amsterdam: John Benjamins, 93-116.

Tribushinina, Elena. 2012. Comprehension of relevance implicatures by preschoolers: The case of adjectives. Journal of Pragmatics 44: 2035-2044.

Tribushinina, Elena \& Steven Gillis. 2012. The acquisition of scalar structures: Production of adjectives and degree markers by Dutch-speaking children and their caregivers. Linguistics 50: $241-268$.

Tribushinina, Elena \& Theo Janssen. 2011. Re-conceptualizing scale boundaries: The case of Dutch helemaal. Journal of Pragmatics 43: 2043-2056. 
Verbuk, Anna. 2009. The role of the lexical component in the acquisition of scalar implicatures. In Jean Crawford, Koichi Otaki \& Masahiko Takahashi, eds. Proceedings of the 3 rd conference on generative approaches to language acquisition. Sommerville, MA: Cascadilla Proceedings Project, 303-312.

Verbuk, Anna \& Thomas Schultz. 2010. Acquisition of relevance implicatures: A case against rationality-based account of conversational implicatures. Journal of Pragmatics 42: 2297-2313.

Von Stechow, Arnim. 1984. Comparing semantic theories of comparison. Journal of Semantics 3: 1-77.

Author's address:

Utrecht Institute of Linguistics

Submitted: 13 March 2013

Utrecht University

Revision invited: 18 May 2013

Trans 10

Revision received: 17 October 2013

3512 JK Utrecht

Accepted: 15 November 2013

The Netherlands

e.tribushinina@uu.nl 